\title{
LETTER
}

\section{Vacuum-assisted closure device in intensive care unit patients and dissemination of Gram-negative bacteria}

\author{
Metaxia N Papanikolaou', Margarita Balla', Panagiotis G Drimousis*1, Anna Xanthaki², Athanasia Tsirigga² \\ and Aikaterini A Charalambous'
}

See related research by Batacchi et al., http://ccforum.com/content/13/6/R194

We read with interest the study by Batacchi and colleagues in a recent issue of Critical Care [1]. Vacuumassisted closure (VAC) decompression is promising for the management of open abdomen, but our limited experience with this system suggests that dissemination of bacteria may occur.

Recently, two patients were treated with VAC in our intensive care unit (ICU). Patient 1 was a 62-year-old man who was originally operated on for paraganglioma and underwent left nephrectomy and gastrojejunal anastomosis. Patient 2 was a 54-year-old woman who was admitted to the ICU two months after a complicated laparoscopic sleeve gastrectomy for morbid obesity. In both patients, at a certain point during their course, intra-abdominal sepsis developed, and they were both managed with extensive debridement, drainage, and VAC placement. Both patients developed fistulas, and although dressings and VAC pump containers were meticulously changed, leaks were repeatedly observed around the dressings.

Furthermore, 2 to 4 weeks after the placement of VAC, a rise of positive cultures for Gram-negative bacteria was observed in all patients in our ICU (Figure 1). As depicted in Figure 2, Klebsiella pneumoniae species became prevalent in our flora despite barrier measures and the isolation of both patients in a separate ward. In 12 out of 34 cases, KPC K. pneumoniae was isolated, whereas in one case it was resistant to all antibiotics.

Recent literature is inconclusive on this subject. We believe that further studies are needed to confirm the dissemination of bacteria from patients with VAC devices and abdominal leaks.

*Correspondence: pdrimousis@hotmail.com

'Intensive Care Unit, Hippokrateion General Hospital, 114, Vas. Sofias Ave. 11521, Athens, Greece

Full list of author information is available at the end of the article

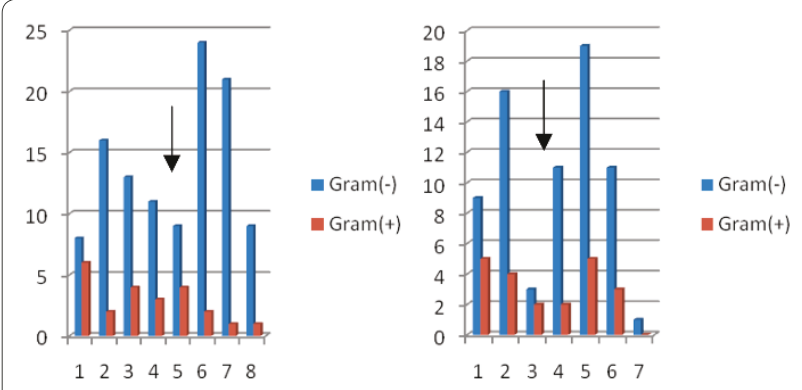

Figure 1. Number of positive Gram-negative and Gram-positive cultures in our intensive care unit during the stay of patients 1 (left) and 2 (right). The arrows represent the time of vacuumassisted closure placement for each patient.

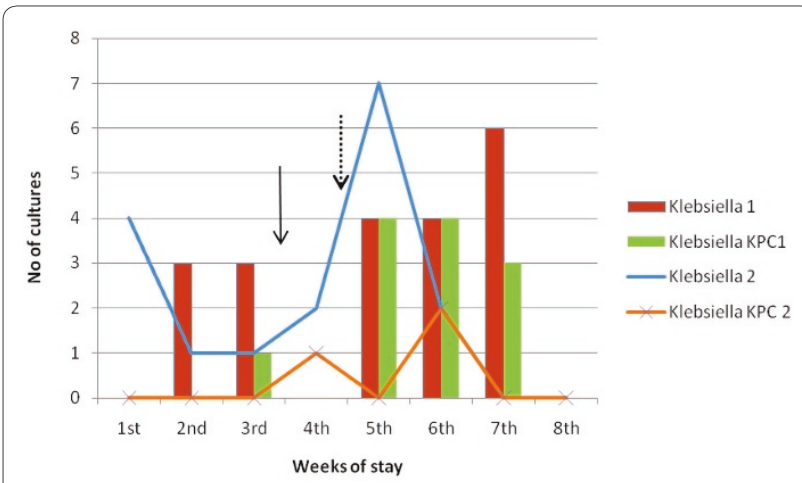

Figure 2. Number of Klebsiella pneumoniae-positive cultures during the stay of patients 1 and 2 . The solid arrow represents vacuum-assisted closure (VAC) placement in patient 1. The dotted arrow represents VAC placement in patient 2.

\section{Authors' response}

\section{Stefano Batacchi, Giovanni Zagli and Adriano Peris}

We appreciate the interest from Papanikolaou and colleagues in our article [1]. In our experience, no patients with VAC developed enterocutaneous fistula, and no evidence is currently available in this regard [2]. 
In the report of Papanikolaou and colleagues, we understand that patients developed fistulas before VAC applications and not as a result of their use. In cases like these, the optimal treatment might be firstly the surgical treatment of the fistula, followed by VAC therapy. Indeed, VAC devices can be used to prevent intestinal fistula formation [2], but to the best of our knowledge, no role for VAC devices in fistula resolution has yet been reported.

In our experience [1], the presence of bacterial colonization was routinely monitored by serial control of the peritoneal fluid drained, and we did not find any microbiological complication. The complication reported by Papanikolaou and colleagues might be ascribed to a preexisting Klebsiella colonization, as described in the figures. Infection diffusion remains a challenge in the ICU and in complicated abdominal surgery. The use of prophylactic procedures (hand washing, gloves, disposable dresses, and dedicated portable devices) by nurses and physicians can reduce this critical problem, and during VAC use in particular, a correct sponge application and efficient planning of vacuum use managed by nurses can help in preventing bacterial colonization. Even a single-room ICU, in our experience, cannot eliminate this complication [3]. However, in our opinion, the bacterial diffusion reported by Papanikolaou and colleagues cannot be attributed to a correct use of a VAC device.

\section{Abbreviations}

ICU, intensive care unit; VAC, vacuum-assisted closure.

\section{Competing interests}

The authors declare that they have no competing interests.

\section{Author details}

'Intensive Care Unit, Hippokrateion General Hospital, 114, Vas. Sofias Ave. 11521, Athens, Greece. ${ }^{2}$ Microbiology Department, Hippokrateion General Hospital, 114, Vas. Sofias Ave. 11521, Athens, Greece.

Published: 19 April 2010

\section{References}

1. Batacchi S, Matano S, Nella A, Zagli G, Bonizzoli M, Pasquini A, Anichini V, Tucci V, Manca G, Ban K, Valeri A, Peris A: Vacuum-assisted closure device enhances recovery of critically ill patients following emergency surgical procedures. Crit Care 2009, 13:R194.

2. Stevens P: Vacuum-assisted closure of laparostomy wounds: a critical review of the literature. Int Wound J 2009, 6:259-66.

3. Bigazzi E, Turrisi L, Zagli G, Pecile P, Bonizzoli M, Peris A: Bay rooms vs singlebed rooms in intensive care unit nosocomial infections: a case-control study. Crit Care 2010, 14 (Suppl 1):P458.

doi:10.1186/cc8944

Cite this article as: Papanikolaou MN, et al:: Vacuum-assisted closure device in intensive care unit patients and dissemination of Gram-negative bacteria. Critical Care 2010, 14:413. 